\title{
Effects of Synthetic Luteinizing Hormone-Releasing Hormone on Plasma Levels of Luteinizing Hormone and Follicle-Stimulating Hormone in Man
}

\author{
Kaoru ABE, NaOKazu NAGATA, Shiro SAITO, Koshi TANAKA, \\ TOSHIO KANEKO, NAOKATA SHIMIZU AND NoBORU YANAIHARA \\ First Department of Internal Medicine, University of Tokyo Faculty of \\ Medicine, Tokyo and Department of Bioorganic Chemistry, \\ Shizuoka College of Pharmacy, Shizuoka
}

\begin{abstract}
Synopsis
Effects of synthetic LH-RH were studied in 5 normal males, 5 normal females and 13 patients with various endocrine or metabolic disorders by measuring plasma $\mathrm{LH}$ and FSH levels. In some normal subjects plasma GH and TSH were determined simultaneously with plasma LH and FSH. The administration of $100 \mu \mathrm{g}$ synthetic LH-RH intramuscularly to normal males and females caused a prompt and marked increase in plasma LH levels. The maximum response was observed at the $30 \mathrm{~min}$ after the injection and the degree of increments was $6-25$ fold in male and 3-6 fold in female. Plasma FSH levels were also increased in 3 male cases and in all female cases, but the degree of responses was smaller as compared with that of plasma LH. A postmenopausal woman with high initial plasma LH and FSH values was responded markedly to synthetic LHRH and the response lasted longer. Synthetic LH-RH had no effects on plasma GH and TSH levels. Patients with pituitary insufficiency failed to show any significant increase in plasma LH and FSH levels in response to synthetic LH-RH. Patients with the other endocrine disorders showed a normal response to synthetic LH-RH as well as 2 cases of anorexia nervosa with amenorrhea. These data indicate that synthetic LH-RH is an useful material to investigate the pituitary gonadotropin reserve in man and that LH-RH has an intrinsic FSH-RH activity, even though it is weaker than LH-RH activity. In addition, the usefulness of this material when employed with the conventional pituitary function tests was discussed.
\end{abstract}

Recently it has become possible to evaluate the pituitary function more precisely by using some stimulators which release pituitary hormone. There are two kinds of stimulators; one is materials which act on the hypothalamus resulting in pituitary hormone release and the other is those to stimulate the pituitary directly. The former is considered to be arginine or insulin etc. which indirectly stimulate $\mathrm{GH}$ secretion and the latter is synthetic thyrotropin releasing hormone (TRH) which directly stimulates the pituitary to release thyrotropin (TSH).

At the middle of 1971, it was proposed

Received for publication December 17, 1971. that an amino acid sequence of porcine luteinizing hormone-releasing hormone (LH$\mathrm{RH}$ ) as (pyro)-Glu-His-Trp-Ser-Tyr-Gly-LeuArg-Pro-Gly- $\mathrm{NH}_{2}$ (Schally et al., 1971; Matsuo et al., 1971). Yanaihara, one of the authors, synthesized LH-RH using a step-bystep method of polypeptide synthesis, which gave us an opportunity to evaluate the effects of this synthetic material in man.

In order to do this, three kinds of approaches were undertaken. First, the release of the pituitary gonadotropin following $\mathrm{LH}-$ $\mathrm{RH}$ administration was determined by measuring plasma levels of luteinizing hormone (LH) and follicle stimulating hormone (FSH) in normal subjects. Second, the effects of 
LH-RH administration on the other pituitary hormones were studied by measuring plasma $\mathrm{GH}$ and TSH levels. And third, the diagnostic usefulness to test pituitary reserve was studied by determing plasma $\mathrm{LH}$ and FSH levels following $\mathrm{LH}-\mathrm{RH}$ injection in patients with endocrine or metabolic disorders.

\section{Materials and Methods}

(Pyro)-Glu-His-Trp-Ser-Tyr-Gly-Leu-Arg-Pro-Gly$\mathrm{NH}_{2}$ (LH-RH) used in this study was a preparation synthesized by one of the authors (Yanaihara) by a step-by-step method of peptide synthesis. It was passed through a millipore filter and then tested to be sterile and nonpyrogenic.

Five normal males aged 20-63 yr, 5 normal females aged 15-49 yr and 13 patients with endocrine or metabolic disorders were examined. The status of menstruation of all female patients was shown in Table 1. and the test was performed in the stage avoided midcycle in cases with regular menstrual cycle.

Four patients with hypopituitarism (one with idiopathic hypopituitarism, one hypophysectomized for chromophobe adenoma and 2 with Sheehan's syndrome) were diagnosed on the bases of clinical findings and usual laboratory tests. Their urinary gonadotropin levels were not detectable and their low plasma values of GH, TSH and cortisol did not change when stimulated by metyrapone, arginine-insulin and synthetic TRH.

All subjects were at bedrest after an overnight fast. After the blood sample was obtained at zerotime $100 \mu \mathrm{g}$ of synthetic LH-RH was administered intramuscularly, and blood samples were drawn at 30,60 , 90 and $120 \mathrm{~min}$ after the injection, except in some cases in those blood samples were obtained at 0,20 , 40,60 , and $90 \mathrm{~min}$. In a case blood samples were collected up to $240 \mathrm{~min}$. Plasma was separated immediately and stored at frozen state until hormone determinations.

Plasma LH, FSH, GH and TSH were measured by the radioimmunoassay techniques using a double antibody system. Plasma cortisol levels were determined by a competitive protein binding assay (Kato et al., 1971). ${ }^{125} \mathrm{I}-\mathrm{LH},{ }^{125} \mathrm{I}-\mathrm{FSH}$ and ${ }^{125} \mathrm{I}$-TSH were prepared by the method of Greenwood et al. (1963). The standard for LH and FSH assays was human pituitary extract reference preparation (LER 907) kindly provided by the National Pituitary Agency, U.S.A., which had $48 \mathrm{mU}$ of $\mathrm{LH}$ and $20 \mathrm{mU}$ of FSH per microgram (bioassay; 2nd 1RP standard). Human
Thyrotropin Research Standard A was used as a standard for TSH. The radioimmunoassay kit for human GH was obtained from the Dainabot Radioisotope Lab, Tokyo.

\section{Results}

Effects of synthetic LH-RH on plasma $\mathrm{LH}$ and FSH levels in normal subjects

The results of the determined plasma LH and FSH values following the intramuscular injection of $100 \mu \mathrm{g}$ synthetic LH-RH in 5 normal males are depicted in Figure 1. In all cases, plasma $\mathrm{LH}$ values were increased significantly with the rise of the initial levels of $0.4-2.3 \mathrm{mU} / \mathrm{m} l$ to $5.2-50.0 \mathrm{mU} / \mathrm{m} l$ at $30 \mathrm{~min}$ and to $3.8-28.1 \mathrm{mU} / \mathrm{ml}$ at $60 \mathrm{~min}$ following the injection. The degree of increments was 6-25 fold at $30 \mathrm{~min}$ and 6-9 fold at $60 \mathrm{~min}$. The maximum response was observed at $30 \mathrm{~min}$ after the injection in all cases and the plasma LH levels were still higher than the initial values at $120 \mathrm{~min}$ after the injection.

Plasma FSH levels were also increased in 3 cases, but the degree of increments was about $2-3$ fold at 30 and 60 min that was much smaller as compared with that observed in plasma LH. The other 2 cases showed some increase in plasma FSH levels, but they were not so significant (Fig. 1).

The data obtained from 5 normal females in response to synthetic LH-RH were shown in Figure 2. The initial plasma $\mathrm{LH}$ values were $1.5-2.8 \mathrm{mU} / \mathrm{m} l$ except a case who was in the postmenopausal stage and had a value of $17 \mathrm{mU} / \mathrm{m} l$. In all cases plasma LH levels were responded markedly to $100 \mu \mathrm{g}$ of synthetic LH-RH and the maximal response was observed at $30 \mathrm{~min}$ in 4 cases and at $60 \mathrm{~min}$ in a case. The degree of increments was 3-6 fold at 30 and $60 \mathrm{~min}$. In all cases the higher than initial values were observed still at 120 min after the injection and especially in a postmenopausal woman a prolonged response was observed. 


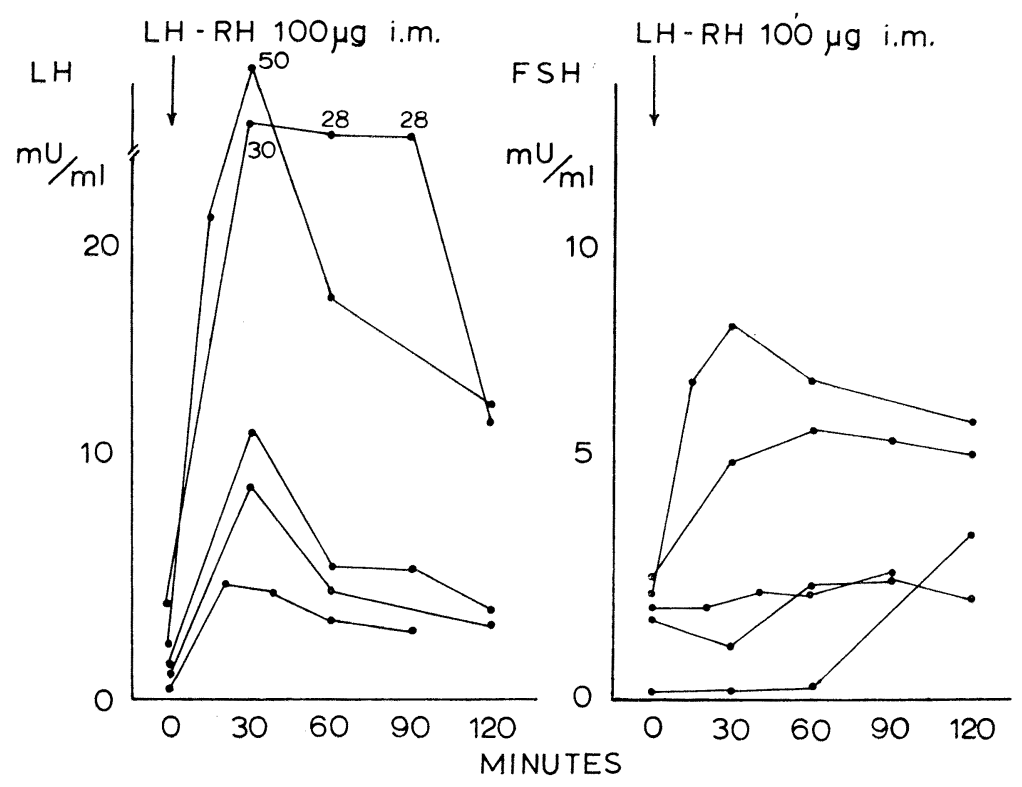

Fig. 1. Plasma LH and FSH levels in response to the intramuscular administration of $100 \mu \mathrm{g}$ synthetic LH-RH in 5 normal males. Note that the ordinate scale of LH is doubled to that of FSH.

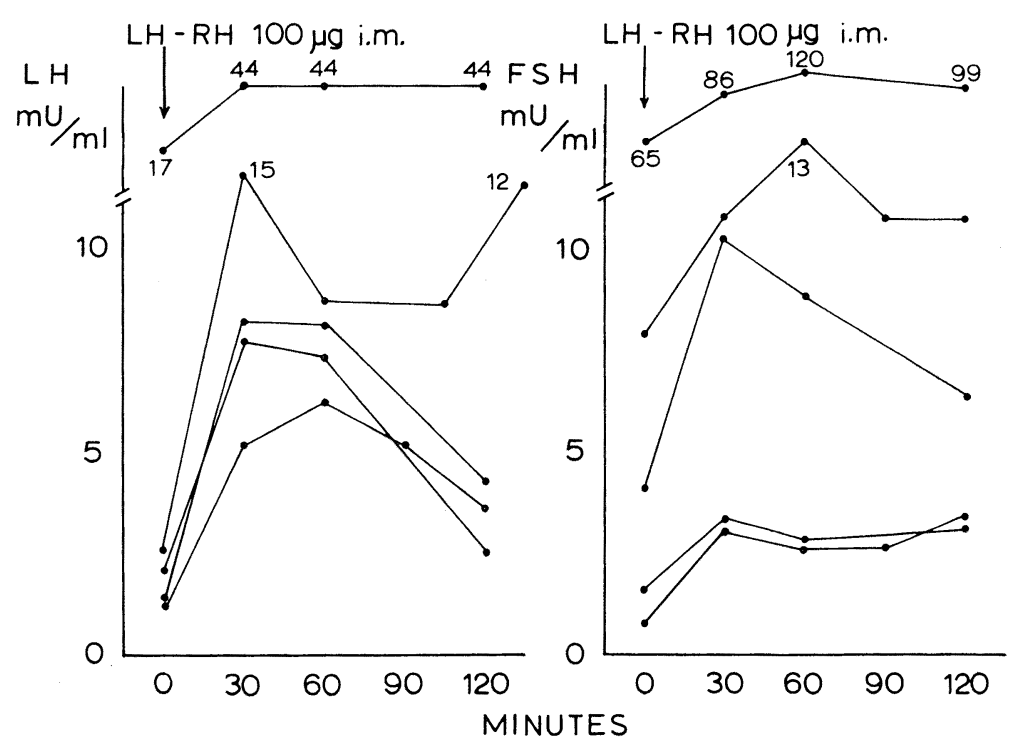

Fig. 2. Plasma LH and FSH levels in response to the intramuscular administration of $100 \mu \mathrm{g}$ synthetic LH-RH in 5 normal females. A case with high plasma LH and FSH levels at the beginning and during the test was a postmenopausal woman aged 49. 
As shown in Figure 2 the response of plasma FSH was also observed in all 5 cases. The responses were moderate with the $2-4$ fold maximum increases of the initial plasma FSH levels. A postmenopausal woman with a high initial values was responded well and the response was prolonged as being observed in case of plasma $\mathrm{LH}$.

\section{Effects of synthetic $\mathrm{LH}-\mathrm{RH}$ on plasma $\mathrm{GH}$ and TSH levels}

Plasma GH and TSH were determined in normal subjects, using the same plasma samples for $\mathrm{LH}$ and FSH determinations. Plasma $\mathrm{GH}$ and TSH measurements were carried out in 6 cases ( 3 males and 3 females). Their plasma LH levels were increased markedly as shown in Figure 1 and 2. However, as shown in Figure 3, plasma GH and TSH levels did not show any significant responses to synthetic LH-RH.

Comparison of the effects of LH-RH with those of clomiphene citrate

Synthetic LH-RH (100 $\mu$ g i.m.) and clomi- phene citrate (50 mg twice daily for 5 days) were administered to the same normal male with one month interval between both tests. As shown in Figure 4, synthetic LH-RH showed a significant and prompt increase in both plasma LH and FSH levels. In contrast, clomiphene citrate showed some increase in both plasma $\mathrm{LH}$ and FSH levels as expected, but it took much longer medication and the degree of responses was much less as compared with that induced by synthetic LH-RH.

Effects of synthetic LH-RH on plasma $\mathrm{LH}$ and FSH levels in patients with various endocrine or metabolic disorders

The clinical informations and plasma LH and FSH values following the synthetic LHRH administration are summarized in Table 1. Four patients with pituitary failure (one with idiopathic hypopituitarism, one hypophysectomized for chromophobe adenoma and 2 patients with Sheehan's syndrome) received $100 \mu \mathrm{g}$ of synthetic LH-RH intramuscularly. In 3 cases there observed no significant increase in plasma $\mathrm{LH}$ and FSH levels in
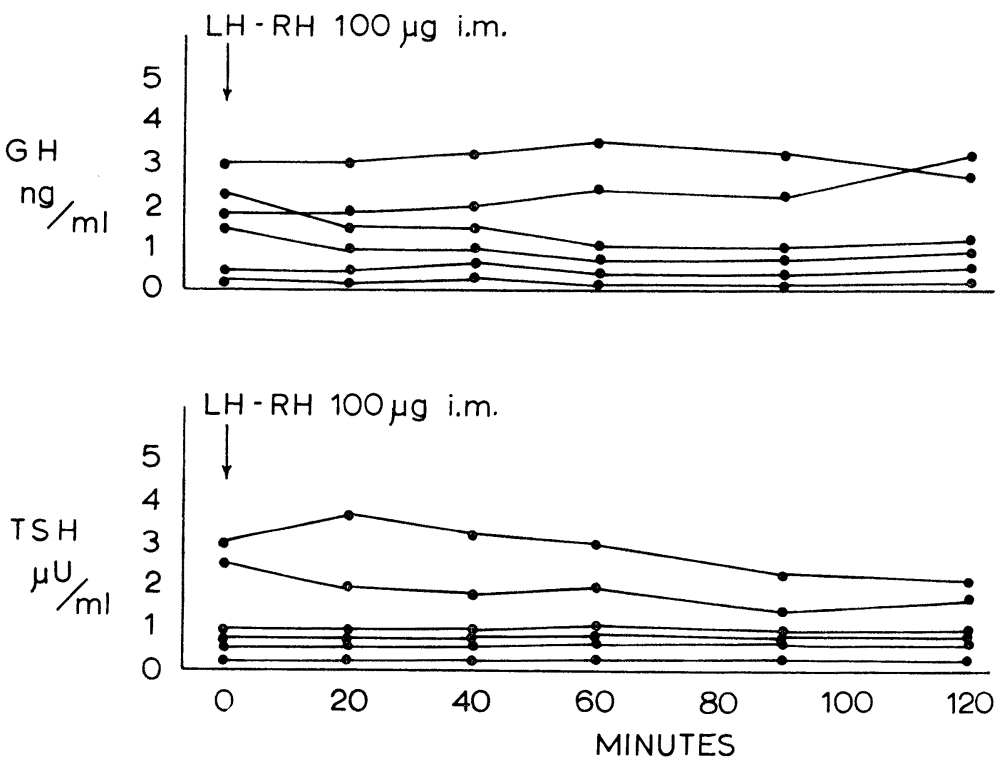

Fig. 3. Effects of the intramuscular injection of $100 \mu \mathrm{g}$ synthetic LH-RH on plasma GH and TSH levels in 6 normal subjects ( 3 males and 3 females). 


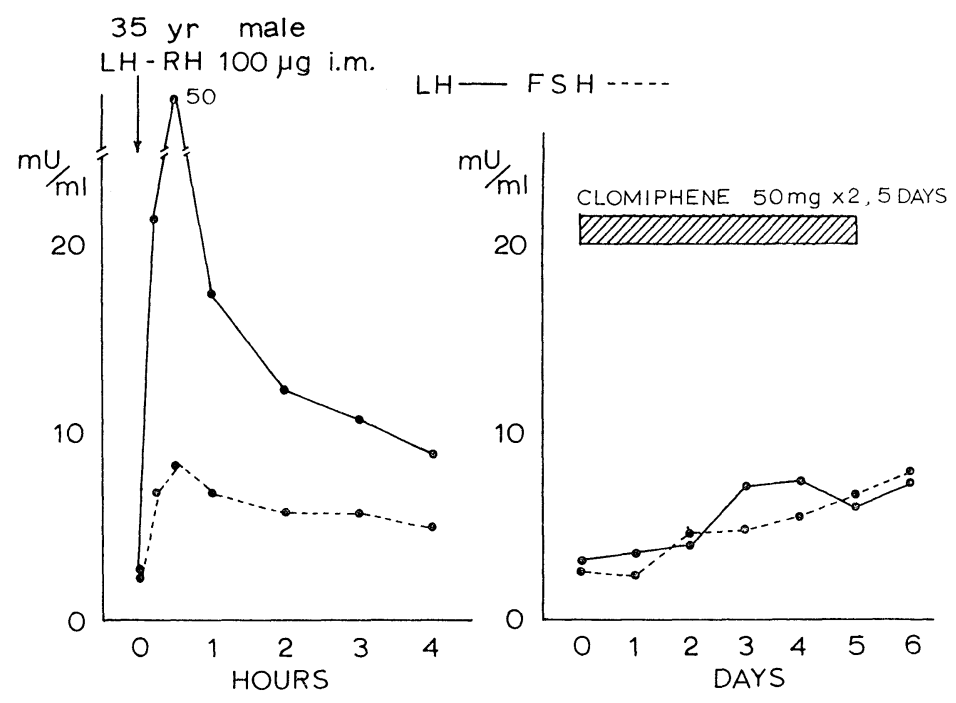

Fig. 4. Comparison of the effects of synthetic LH-RH with those of clomiphene citrate on plasma LH and FSH levels. Synthetic LH-RH (100 $\mu \mathrm{g}$ i.m.) and clomiphene citrate (50 mg twice daily for 5 days) were administered to a same normal male with one month interval between the 2 tests. The solid lines indicate plasma LH levels and the dotted lines plasma FSH levels.

Table 1. Plasma LH and FSH in response to synthetic LH-RH in patients with endocrine or metabolic disorders

\begin{tabular}{|c|c|c|c|c|c|c|c|c|c|c|c|c|c|c|}
\hline \multirow[b]{2}{*}{ Case } & \multirow[b]{2}{*}{ Name } & \multirow{2}{*}{\multicolumn{2}{|c|}{ Age Sex }} & \multirow[b]{2}{*}{ Diagnosis } & \multicolumn{5}{|c|}{$\mathrm{LH} \quad \mathrm{mU} / \mathrm{m} l$} & \multicolumn{5}{|c|}{$\mathrm{FSH} \mathrm{mU} / \mathrm{m} l$} \\
\hline & & & & & 0 & $\begin{array}{l}30 \\
(\mathrm{mir}\end{array}$ & $\begin{array}{c}60 \\
\text { in after }\end{array}$ & $\begin{array}{c}90 \\
100\end{array}$ & $\begin{array}{c}120 \\
\mu \mathrm{g} \text { of } \mathrm{I}\end{array}$ & $\begin{array}{c}0 \\
\text { LH-R }\end{array}$ & $\begin{array}{r}30 \\
\mathrm{H} \text { adn }\end{array}$ & $\begin{array}{c}60 \\
\text { ministr }\end{array}$ & $\stackrel{90}{\text { ration) }}$ & ) 120 \\
\hline 1 & FB & 22 & M & Hypopituitar & 1.3 & 7.9 & 6 & 6.3 & 4.4 & 0.7 & 1.8 & 1.8 & 2.0 & 2.0 \\
\hline 2 & KK & 30 & M & Hypopituitarism, $\overline{\mathrm{p}}$ op. & 0.8 & 1.3 & 0.9 & 1.9 & 1.3 & $<0.3$ & $<0.3$ & $<<0.3$ & $<0.3$ & $<0.3$ \\
\hline 3 & SI & 40 & $\mathrm{~F}$ & Sheehan's syndrome & 1.9 & 2.5 & 2.5 & & 3.0 & 3.1 & 2.8 & 2.8 & & 3.0 \\
\hline 4 & KK & 41 & $\mathrm{~F}$ & Sheehan's syndrome & 0.4 & 1.1 & 1.3 & 1.3 & 1.5 & 1.3 & 1.8 & 2.0 & 2.5 & 2.7 \\
\hline 5 & MF & 43 & $\mathrm{~F}$ & Nelson's syndrome & 2.6 & 14.8 & 13.0 & 10.4 & 8.8 & 1.2 & 1.9 & 2.7 & 2.7 & 3.4 \\
\hline 6 & $\mathrm{SH}$ & 53 & $\mathbf{M}$ & Diabetes insipidus, idiopathic & 0.1 & 2.2 & 2.0 & 1.3 & 1.5 & 1.1 & 1.6 & 2.4 & 2.2 & 2.0 \\
\hline 7 & $\mathrm{KT}$ & 20 & $\mathrm{~F}$ & Obesity & 1.5 & 8.3 & 8.3 & & 5.2 & 4.1 & 10.5 & 8.8 & & 6.3 \\
\hline 8 & FT & 18 & $\mathrm{~F}$ & Hypochromic & 1.5 & 4.3 & 4.3 & & 3.6 & 5.1 & 6.3 & 7.5 & & 7.5 \\
\hline 9 & TT & 18 & M & Hypoparathyroidism, idiopathic & 1.1 & 11.0 & 8.3 & & 5.2 & 3.3 & 8.8 & 7.5 & & 7.5 \\
\hline 10 & TH & 24 & $\mathrm{M}$ & Hyperthyroidism & 2.2 & 23.0 & 17.0 & 14.8 & 7.2 & 1.3 & 4.4 & 4.4 & 4.4 & 4.1 \\
\hline 11 & KS & 49 & $\mathrm{~F}$ & Hypothyroidism, primary & 12.1 & 125 & 125 & 125 & 68 & 50 & 99 & 145 & 145 & 145 \\
\hline
\end{tabular}

Case 2 was operated for chromophobe adenoma and has been under the treatment of $100 \mu \mathrm{g}$ triiodothyronine and $20 \mathrm{mg}$ cortisol daily for 2 years. Case 5 has been receiving $30 \mathrm{mg}$ cortisol daily for 15 months. Case 6 has been well controled with $250 \mathrm{mg}$ chlorpropamide daily for 3 years. Case 5 and 7 had normal menses, but case 3, 4 and 8 complained of amenorrhea. Case 11 was a postmenopausal woman.

response to synthetic $\mathrm{LH}-\mathrm{RH}$, but in a patient with idiopathic hypopituitarism, plasma LH and FSH values showed a normal response to synthetic LH-RH. Since he failed to respond to metyrapone, arginine and $\mathrm{TRH}$, this case was diagnosed to have partial hypopituitarism. 
In a patient with postadrenalectomy Cushing's disease (Nelson's syndrome), who had been receiving $30 \mathrm{mg}$ cortisol daily, there observed a significant increase in plasma $\mathrm{LH}$ levels and a slight increase in plasma FSH levels in response to synthetic LH-RH.

In a patient with idiopathic diabetes insipidus who was under the treatment of $250 \mathrm{mg}$ chlorpropamide per day, the plasma LH and $\mathrm{FSH}$ responses to synthetic LH-RH were moderate.

In 2 young females, one with obesity and the other with amenorrhea due to hypochromic anemia, plasma LH and FSH were responded to the synthetic LH-RH administration as normal subjects.

A patient with idiopathic hypoparathyroidism and a patient with hyperthyroidism showed a normal plasma LH and FSH increase in response to synthetic LH-RH.

A postmenopausal patient with primary hypothyroidism aged 49 showed high initial plasma levels of $\mathrm{LH}$ and $\mathrm{FSH}$, which were responded excessively and prolongedly to the synthetic LH-RH administration.

\section{Effects of synthetic $L H-R H$ in patients with amenorrhea}

Synthetic LH-RH was injected intramuscularly to 4 patients with amenorrhea. Two were patients aged 40 and 41 with Sheehan's syndrome and 2 were patients aged 19 and 21 with anorexia nervosa. As shown in Figure 5, plasma LH and FSH levels were increased markedly in response to synthetic LH-RH in patients with anorexia nervosa. In contrast, plasma LH and FSH levels in patients with Sheehan's syndrome did not show any significant responses.

\section{Side effects}

There were no toxic effects in any subjects received $100 \mu \mathrm{g}$ synthetic LH-RH intramuscularly. Pulse, respiration and blood pressure showed no change, and there was no disturbing subjective sensation.

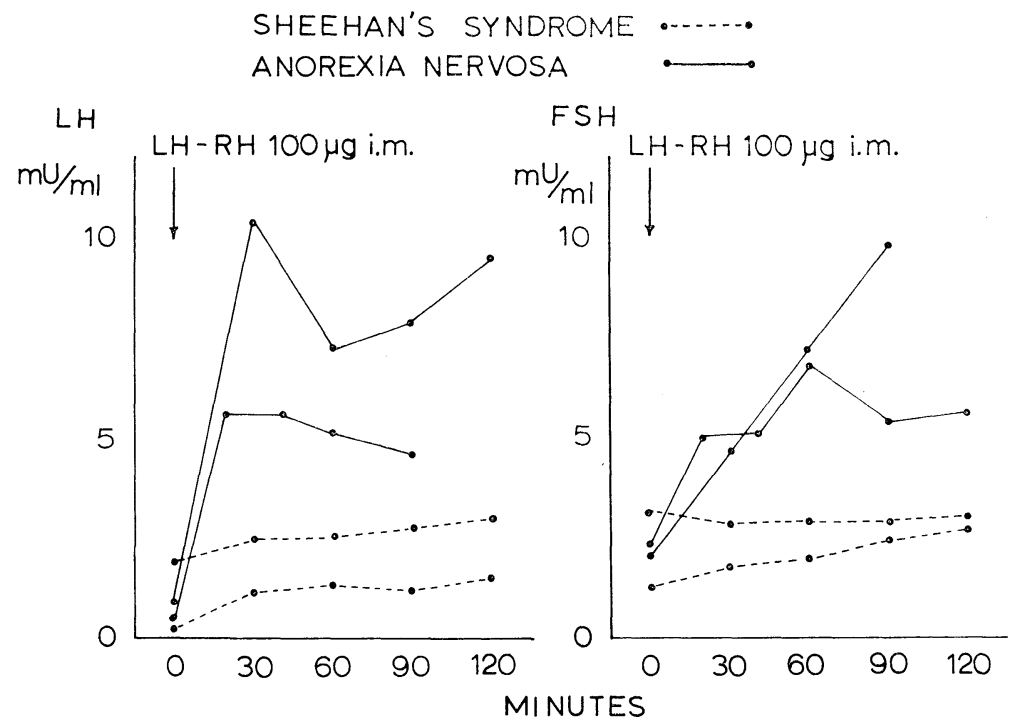

Fig. 5. Plasma LH and FSH levels in response to the intramuscular administration of $100 \mu \mathrm{g}$ synthetic LH-RH in 2 patients with Sheehan's syndrome and 2 patients with anorexia nervosa. The solid lines indicate the responses of the patients with anorexia nervosa and the dotted lines indicate the responses of patients with Sheehan's syndrome. The results of 2 Sheehan's cases were also shows in Table 1. 


\section{Discussion}

Since the whole structure of LH-RH was identified, an attempt has been made in several laboratories to synthesize this material and to evaluate its activity. (Matsuo et al., 1970; Schally et al., 1971; Nagata et al., 1971). Yanaihara, one of the authors, synthesized LH-RH using a step-by-step method of peptide synthesis. It has been reported here that this material had no side effect when given intramuscularly at a dose of $100 \mu \mathrm{g}$. In normal males and females, plasma LH levels were increased significantly in response to synthetic $\mathrm{LH}-\mathrm{RH}$ with the peak values at $30 \mathrm{~min}$ following the injection, and plasma FSH levels were also increased in most of the cases, but the degree of increments was less as compared with that of plasma LH. The administration of synthetic LH-RH did not produce any significant changes of plasma GH and TSH levels. These data indicate that synthetic LH-RH is an useful material to evaluate the pituitary gonadotropin reserve in man.

It is well known that the determinations of plasma LH and FSH levels alone are not sufficiently enough to estimate the pituitary gonadtropin reserve (Odell et al., 1967, 1968; Ryan et al., 1970), because there exists some overlap between plasma LH and FSH levels of normal subjects and those of patients with hypopituitarism, except those who are in postmenopausal ages. In order to differentiate these situations, clomiphene has been employed, which is known to act on the hypothalamus resulting in to secrete $\mathrm{LH}$ and FSH from the pituitary (Bardin et al., 1967; Fiedler et al., 1969). However, clomiphene is usually required more than 3 days medication to observe a significant increase in plasma LH and FSH levels (Odell et al., 1967; Geller et al., 1970). In addition, as reported here, the degree of responses is not so large as compared with that obtained by synthetic LH-RH.
Our data obtained from patients with endocrine or metabolic disorders clearly indicate that synthetic LH-RH is a good material to differentiate those with pituitary failure from the others.

It should be mentioned here that a patient with idiopathic hypopituitarism showed a normal increase in plasma $\mathrm{LH}$ and FSH in respone to the synthetic LH-RH administration. Since he failed to respond to metyrapone, arginine and $\mathrm{TRH}$, this case was diagnosed to have a partial hypopituitarism. These data suggest that the pituitary function should be examined for individual pituitary hormone by employing a proper stimulus to each as we mentioned elsewhere (Saito and Abe, 1972).

It is interesting that the cases with high initial LH and FSH values were responded well to synthetic LH-RH and their responses usually lasted longer. The similar situation has been reported in patients with primary hypothyroidism, who had high plasma TSH levels which were responded markedly and prolongedly to the administration of synthetic TRH (Hershman and Pittman, 1970; Saito et al., 1971; Gual et al., 1972). These data may suggest that the pituitary of these patients is working actively to release excessive amount of hormone, which makes it susceptive to the administration of releasing hormones.

It has been reported that a highly purified LH-RH caused a significant increase in plasma LH and FSH values (Kastin et al., 1969) and the present study employed synthetic LH-RH again demonstrated that LH-RH released FSH as well as $\mathrm{LH}$, even though the response of FSH was less as compared with that of LH, supporting a view that LH-RH has an intrinsic activity of FSH-RH (Schally et al., 1917a, 1971b; Kastin et al., 1971).

We are now employing LH-RH, TRH, arginine and insulin to evaluate the pituitary function, which give us enough amount of informations about the status of individual anterior pituitary hormone except prolactin. LH-RH and TRH are a material of natural 
source to stimulate the pituitary directly and the administration of arginine or insulin is stimulus which acts via the hypothalamus resulting in to secrete releasing hormones. The proper combination of these stimuli would give more detailed and precise informations about the pituitary function.

It seems to us that the clinical application of synthetic LH-RH is much more significant when compared to TRH, because it can be used not only as an important test material to evaluate the pituitary gonadtropin reserve, but also it could be used as a medicine to provoke the ovulation in some type of patients with amenorrhea.

\section{Acknowledgements}

We are grateful to Dr. Tatsuo Kato for measuring plasma cortisol levels and to Dr. Etsuro Ogata for referring a patient, to Miss Sumiko Miyata for skillful technical assistance.

We wish to acknowledge the National Pituitary Agency, Endocrinology Study Section, and National Institute of Arthritis and Metabolic Diseases, U.S.A. for the generous supplies of the radioimmunoassay kits for human TSH, FSH and LH. Human Thyrotropin Research Standard A was kindly supplied by the National Institute for Medical Research, England.

\section{References}

Bardin, C. W., G. T. Ross and M. B. Lipsett (1967). J. Clin. Endocrinol. 27, 1558.

Geller, J., A. Baron and S. Kleinman (1970). J. Endocrinol. 48, 289.

Greenwood, F. C., W. M. Hunter and J. S. Glover (1963). Biochem. J. 89, 114.

Gual, C., A. J. Kastin and A. V. Schally (1972). Rec. Progr. Hormone Res. (in press).
Heller, C. G., M. J. Rowley and G. V. Heller (1969). J. Clin. Endocrinol. 29, 638.

Hershman, J. M. and J. A. Pittman, Jr. (1970). J. Clin. Endocrinol. 31, 457.

Kato, T. and T. Ito (1971). Nippon Rinsyo 29, 1065 (In Japanese).

Kastin, A. J., A. V. Schally, C. Gual, A. R. Midgley, Jr., C. Y. Bowers and A. DiazInfante (1969). J. Clin, Endocrinol. 20, 1046.

Kastin, A. J., A. V. Schally, C. Gual, A. R. Midgley, Jr., M. C. Miller, III and A. Cabeza (1971). J. Clin. Invest. 50, 1551.

Matsuo, H., Y. Baba, R. M. G. Nair, A. Arimura and A. V. Schally (1971). Biochem. Biophys. Res. Comm. 43, 1334.

Nagata, N., S. Saito, K. Abe, K. Tanaka, T. Kaneko, E. Nakamura, N. Shimizu and N. Yanaihara (1972). Igaku no Ayumi, (in press, In Japanese).

Odell, W. D., G. T. Ross and P. L. Rayford (1967). J. Clin, Invest. 46, 248.

Odell, W. D., A. F. Parlow, C. M. Gargille and G. T. Ross (1968). Ibid. 47, 2551.

Ryan, R., M. D. Cloutier, A. B. Hayles, J. Paris and R. V. Randoll (1970). Med. Clinics of North Amer. 54, 1049.

Schally, A. V., A. Arimura, Y. Baba, R. M. G. Nair, H. Matsuo, T. N. Redding and L. Debeljuk (1971a). Biochem. Biophys. Res. Comm. 43, 393.

Schally, A. V., A. Arimura, A. J. Kastin, H. Matsuo, Y. Baba, T. W. Redding R. M. G. Nair, L. Debeljuk, and W. F. White (1971b). Science 173, 1036.

Saito, S., K. Abe, H. Yoshida, T. Kaneko, E. Nakamura, N. Shimizu and N. Yanaihara (1971). Endocrinol. Japon. 18, 101.

Saito, S. and K. Abe (1972). Hormone To Rinsyo. 20, 85. (In Japanese). 